\title{
Contrast-enhanced whole heart coronary MRI with a bolus infusion of gadobenate dimeglumine at $1.5 \mathrm{t}$
} Peng $\mathrm{Hu}^{* 1}$, Jonathan Chan ${ }^{1}$, Jouke Smink ${ }^{2}$, Beth Goddu ${ }^{1}$, Kraig V Kissinger ${ }^{1}$, Lois Goepfert ${ }^{1}$, Warren J Manning ${ }^{1}$ and Reza Nezafat ${ }^{1}$

Address: ${ }^{1}$ Beth Israel Deaconess Medical Center, Boston, MA, USA and 2 Philips Healthcare, Best, Netherlands

* Corresponding author

from 13th Annual SCMR Scientific Sessions

Phoenix, AZ, USA. $21-24$ January 2010

Published: 21 January 2010

Journal of Cardiovascular Magnetic Resonance 20 I0, I2(SuppI I):P5I doi: I0.I I86/I532-429X-I2-SI-P5 I

This abstract is available from: http://jcmr-online.com/content/|2/SI/P5 I

(c) $2010 \mathrm{Hu}$ et al; licensee BioMed Central Ltd.

\section{Introduction}

The potential benefits of contrast agents have been studied for coronary MRI; however the contrast timing/injection rate and sequence remain to be optimized. We investigated three infusion schemes (bolus, hybrid, slow) of gadobenate dimeglumine ([Gd-BOPTA ${ }^{2-}$, MultiHance; Bracco Imaging SpA, Milan, Italy), a high relaxivity extracellular contrast agent, for improved whole-heart coronary MRI by measuring blood $\mathrm{T}_{1}$ kinetics. Subsequently, we developed a contrast-enhanced whole-heart coronary MRI method at $1.5 \mathrm{~T}$ using an inversion-recovery SSFP sequence acquired after a bolus infusion.

\section{Methods}

Four healthy adult subjects were imaged three times each using three infusion schemes: a) bolus (0.2 mmol $/ \mathrm{kg} @ 2 \mathrm{ml} /$ $\mathrm{s})$, b) hybrid $(0.1 \mathrm{mmol} / \mathrm{kg} @ 2 \mathrm{ml} / \mathrm{s}$ plus $0.1 \mathrm{mmol} / \mathrm{kg} @ 0.1 \mathrm{ml} /$ s), and c) slow (0.2mmol $/ \mathrm{kg} @ 0.3 \mathrm{ml} / \mathrm{s})$. A Look-Locker sequence was used for quantitative $\mathrm{T}_{1}$ measurements. Subsequently, seven healthy subjects were recruited for evaluation of a contrast-enhanced whole-heart coronary MRI with a bolus infusion. Free-breathing SSFP coronary MRI $\left(\mathrm{TR} / \mathrm{TE} / \alpha=3.6 / 1.8 / 90^{\circ}, \mathrm{FOV}=300 \times 300 \times 120 \mathrm{~mm}^{3}\right.$, resolution $=1.3 \times 1.3 \times 1.3 \mathrm{~mm}^{3}, \mathrm{~T}_{2}$-Prep, $\times 2$ accelerated) was performed before contrast injection. Gd-BOPTA $(0.2 \mathrm{mmol} / \mathrm{kg} @ 2 \mathrm{ml} / \mathrm{s})$ was injected intravenously, immediately followed by a Look-Locker sequence to visually determine the optimal inversion time. A contrastenhanced whole-heart coronary was then acquired with identical imaging parameters with the exception of replac- ing the $\mathrm{T}_{2}$-Prep with a non-selective inversion pulse. For both acquisitions, a noise scan was performed immediately after acquisition. The blood SNR and blood-myocardium CNR were measured.

\section{Results}

Figure 1 shows the blood $\mathrm{T}_{1}$ during the first 10 min after contrast injection. The bolus injection yields the fastest

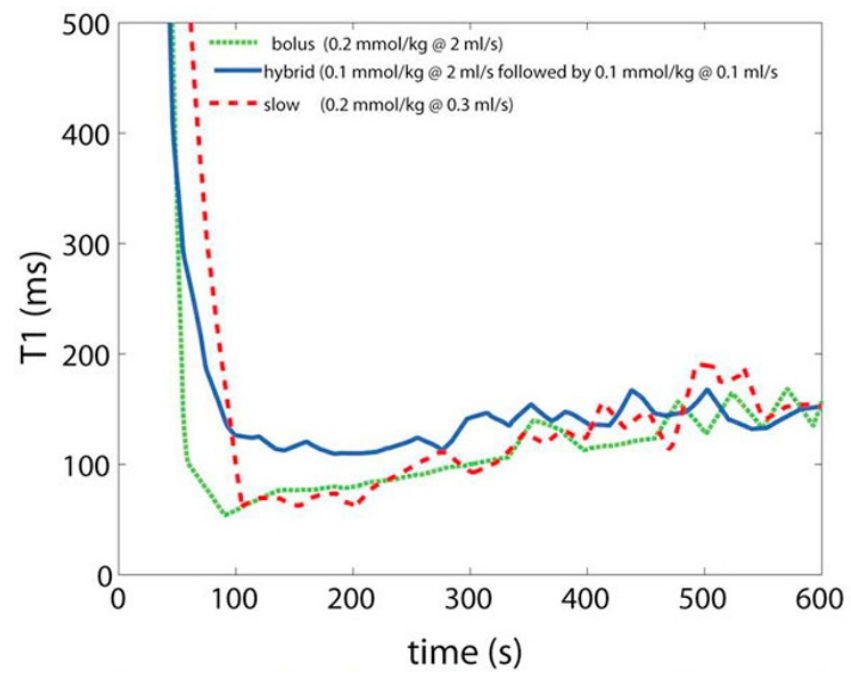

\section{Figure I}

Time course of blood $T_{1}$ up to 10 minutes after contrast injection using three infusion schemes. 

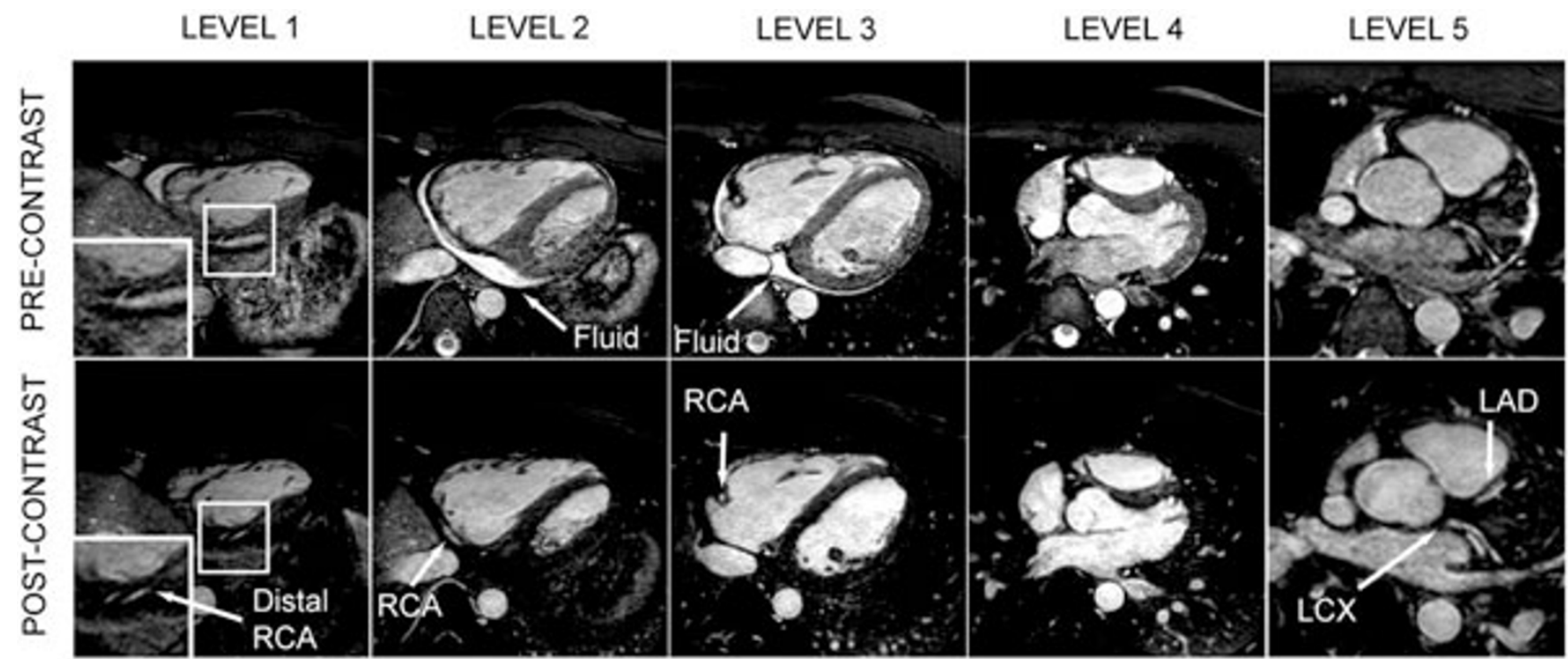

Figure 2

Example coronary images acquired on a healthy subject using an SSFP sequence before (top row) and after (bottom row) a bolus injection of Gd-BOPTA.

and largest $T_{1}$ reduction in the initial 1-2 minutes. Slow infusion reduces the $T_{1}$ at a slower pace than bolus, but was similar to bolus $\sim 2-3$ min after injection. A hybrid infusion results in the lowest decrease in $\mathrm{T}_{1}$, but also the most stable. Figure 2 shows a comparison of contrastenhanced and non-contrast coronary images. The coronary SNR and CNR were significantly improved by $36 \%$ (58.5 \pm 18.7 vs. $79.5 \pm 17.5)$ and $101 \%(27.3 \pm 11.4$ vs.

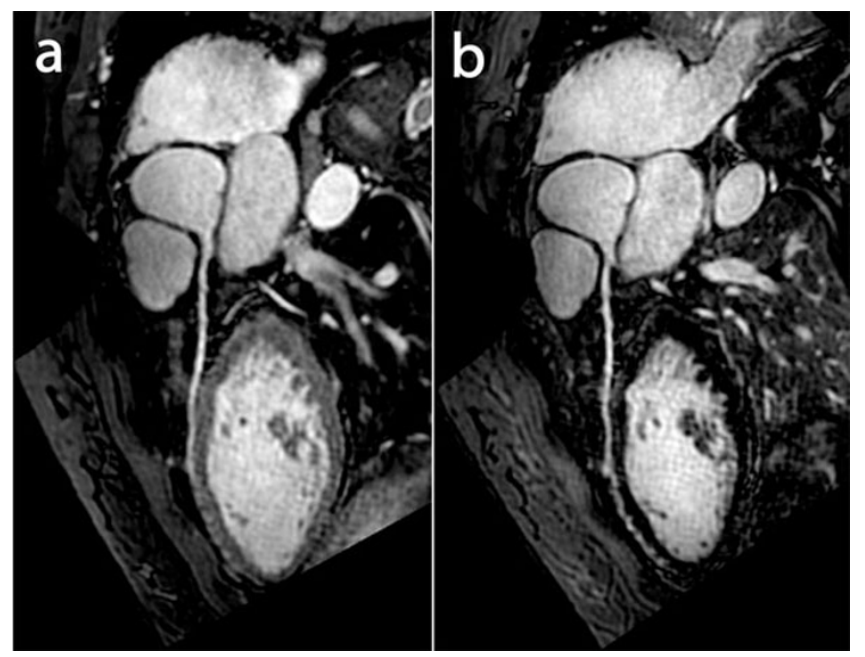

Figure 3

Reformatted non-contrast (a) and contrast-enhanced (b) LAD images. The improved suppression of myocardial signal using Gd-BOPTA facilities depiction of mid and distal right coronary artery.
$55.0 \pm 12.1)$, respectively ( $<0.003$ for both). Figure 3 shows reformatted examples of the LAD, which shows improved visualization of mid and distal LAD.

\section{Conclusion}

Contrast-enhanced whole heart coronary MRI with a bolus infusion of Gd-BOPTA using inversion-recovery SSFP at 1.5 T results in enhanced SNR and CNR.
Publish with Bio Med Central and every scientist can read your work free of charge

"BioMed Central will be the most significant development for disseminating the results of biomedical research in our lifetime. " Sir Paul Nurse, Cancer Research UK

Your research papers will be:

- available free of charge to the entire biomedical community

- peer reviewed and published immediately upon acceptance

- cited in PubMed and archived on PubMed Central

- yours - you keep the copyright
BioMedcentral 